\title{
Transvaginal sonographic evaluation at different menstrual cycle phases in diagnosis of uterine lesions
}

This article was published in the following Dove Press journal:

International Journal of Women's Health

25 October 20II

Number of times this article has been viewed

\section{Masomeh Hajishaiha' \\ Mohammad Ghasemi-rad ${ }^{2}$ \\ Nazila Karimpour' \\ Nikol Mladkova ${ }^{3}$ \\ Farzaneh Boromand ' \\ 'Department of Gynecology, ${ }^{2}$ Student Research Committee (SRC), Urmia University of Medical Sciences, Urmia, Islamic Republic of Iran; ${ }^{3}$ Institute of Cell and Molecular Science, London, UK}

Correspondence: Mohammad

Ghasemi-rad

Genius and Talented Student

Organization, Student Research Center

(SRC), Urmia University of Medical

Sciences, Urmia, Islamic Republic of Iran

Tel +989143485284

Fax +9844123535

Email medmanII@gmail.com
Purpose: Intrauterine lesions (IULs) are a common finding in women of reproductive age, particularly infertile women. Transvaginal sonography (TVS) is a popular tool for IUL detection, but there are conflicting data with respect to its accuracy.

Methods: Five hundred and six women were enrolled into the study. Of these, 496 underwent hysterosalpingography and subsequent TVS six different times during the course of their menstrual cycle. If a lesion was detected, it was further evaluated by sonohysterography (SHG) and hysteroscopy.

Results: Of 496 women, 41 were shown to have IULs by TVS and those lesions were confirmed in 39 by SHG and hysteroscopy. All 39 lesions were detectable during the ovulatory and early luteal phase (days 16-19) of the menstrual cycle. Accuracy of TVS during different phases was largely dependent on the size of the lesion. TVS falsely detected two lesions and missed fine adhesions in two patients.

Conclusion: Accuracy of TVS in detection of IULs is highly dependent on the menstrual cycle phase, with the ovulatory and early luteal phase being the optimal time for this examination.

Keywords: menstrual cycle phase, space occupying lesions, transvaginal sonography

\section{Introduction}

Structural pathologies in the uterine cavity are well-established as factors associated with infertility. Intrauterine lesions (IULs) have been linked generally to fertility reduction and more specifically to implantation failure and miscarriage. ${ }^{1}$ The most commonly suspected intrauterine pathologies involved in infertility include endometrial polyps, shown to affect $9.4 \%-39.4 \%$ of infertile women, ${ }^{2,3}$ submucosal fibroids, adhesions, and uterine malformations. Efficient detection and adequate management of lesions is imperative in infertile women so optimal infertility treatment can proceed.

Hysterosalpingography (HSG) is a radiological modality most commonly used for the assessment of the uterine cavity. Although HSG is generally accepted as the initial diagnostic procedure performed in infertile women, several disadvantages are inherent to the technique, ${ }^{4}$ including exposure to ionizing radiation and the injection of radio-opaque material. Sonohysterography ( $\mathrm{SHG}$ ), described in detail elsewhere, ${ }^{5}$ has rapidly become a popular tool for the diagnosis of intrauterine pathologies. ${ }^{6}$ In spite of its unequivocal advantages, such as low cost and the fact that patients are not subjected to ionizing radiation, the procedure is more time consuming than HSG and can lead to vasovagal shock in certain patients. ${ }^{5}$ SHG has yet to be presented as an alternative gold standard for investigating the uterine cavity. ${ }^{6}$

Hysteroscopy, however, is considered a gold-standard technique for uterine cavity examination, since it allows direct visualization of potential lesions and can be paired with 
biopsy if necessary. Nevertheless, this procedure is invasive and often requires anesthesia and specialized equipment (ie, a hysteroscope). Moreover, hysteroscopy is more costly than HSG or SHG and does not provide information about the external morphology of the organ, ${ }^{7}$ myometrium, or adnexa. ${ }^{8}$

Transvaginal sonography (TVS) is a simple, painless, and cost-effective examination that is capable of providing accurate information about IULs and is not associated with adverse pregnancy outcomes. ${ }^{9,10}$ However, studies of the diagnostic accuracy of TVS have produced conflicting results. ${ }^{10-16}$ Since specific disorders of the intrauterine cavity are most efficiently diagnosed at different phases of the menstrual cycle, ${ }^{17}$ the conflicting results of previous reports may be at least partially due to this factor, in addition to interobserver bias. Uterine lesions could be the reason for infertility in $10 \%$ to $15 \%$ of cases. ${ }^{5}$

Identification of an efficient, accessible, painless, and reliable tool in the diagnosis of IULs is of great importance in the care of infertile patients, and the aim of the present study was to evaluate the diagnostic accuracy of TVS in the detection of intrauterine abnormalities during different phases of the menstrual cycle in infertile women. TVS was compared with SHG and hysteroscopy, which represent the gold standard in the evaluation of IULs.

\section{Patients and methods}

The study protocol was approved by the Institutional Review Board and Ethics Committee of the University of Medical Sciences in Urmia, Iran. Written informed consent was obtained from all participants in the presence of a witness. All patients were free to withdraw from the study at any time and for any reason.

Five hundred and six infertile females attending the Center for Infertility Treatment and Research of Shahid Mottahari Hospital in Urmia, Iran, were consecutively enrolled in the study between September 2008 and February 2009. Patients' infertility was defined as a failure to conceive after 1 year of unprotected intercourse. ${ }^{5}$ This center is the only infertility clinic in the West Azerbaijan province of Iran and all infertile patients in the area are referred exclusively to this center.

All participants initially underwent routine infertility work-up consisting of hormone testing (luteinizing hormone, follicle-stimulating hormone, prolactin, thyroid-stimulating hormone, estradiol), hysterosalpingography, and their partner's semen was analyzed. In addition, the couple's etiology of infertility and the regularity of the woman's menstrual cycle were noted. Further participation in the study was dependent on the detection of IULs with HSG. Patients with no detectable IULs attempted assisted reproduction (AR) consisting of either intracytoplasmic sperm injection or intrauterine insemination. Women attempting AR and women with detected lesions underwent TVS every 3-4 days starting from the first day of their menstrual cycle. In women attempting AR, TVS was used to evaluate the intrauterine cavity and to monitor follicular development and ovulation. In total, each patient underwent TVS six times. Phases of the menstrual cycle during which the lesion was visible or invisible were recorded. If an intrauterine pathology was detected with TVS, the finding was explained to participants and those patients were then candidates to undergo SHG.

SHG was performed during the follicular phase, 2 days after the last menstrual period. Before the procedure was performed, all patients were examined by a gynecologist and by TVS to exclude the presence of fluid in the cul-de-sac (retrounterine pouch). The patients were also asked to refrain from intercourse before the examination. Pregnant patients, patients with sexually transmitted diseases, with fluid in the cul-de-sac, or with abnormal uterine bleeding were excluded from the study. If an IUL was confirmed with SHG, the patient underwent further hysteroscopy during which the lesion was resected.

TVS was performed by a physician with 10 years' experience (MH); hysteroscopy was performed by another reproduction specialist with 12 years' experience (FB); a radiologist with 20 years' experience, who had no knowledge of the ultrasonographic results, performed SHG.

\section{Results}

Twelve of the 506 patients had IULs detectable by HSG and were referred for further treatment. These patients also underwent TVS every 3-4 days and TVS was able to detect the lesions in all cases. The remaining 492 patients attempted AR and also underwent TVS with the same frequency as patients with detected lesions, a total of six times. Of those, 29 had TVS-detectable IULs, yielding a total of 41 women $(12+29,8 \%)$ with detectable IULs in the study.

The ages of the 41 women ranged from 19 to 42 years (mean age 31 years). Thirty-one (75\%) suffered from primary and ten (25\%) from secondary infertility. In 19 (46\%) women, the infertility etiology was unknown; in twelve (29\%) it was caused by a male factor, in five $(12 \%)$ by anovulation and in another five by tubal factor. Thirty-two (78\%) had regular menses and nine (22\%) irregular.

The 41 patients with detectable IULs underwent SHG, which confirmed the lesions in 39 (95\%) patients, and two (5\%) showed false positive results (which were possibly due to blood clots). Of the 41 with detectable IULs, 39 had a submucosal myoma and 35 had an intrauterine polyp (38 single and only one double lesion). There were 35 polyps and 
four submucosal leiomyomas. Lesions were mostly 5-10 mm in size but there were some up to $20 \mathrm{~mm}$.

As a control, women with no detectable lesion on TVS were offered the option of undergoing SHG. Of 465 patients, 122 consented and two of those were shown to have delicate adhesions previously undetected by TVS.

\section{Correlation between menstrual cycle and detection of IULs}

All 39 SHG-confirmed lesions were detectable by TVS between days 16 and 19 of the menstrual cycle. Of those, nine were not detectable between days 20 and 24 and 20 were undetectable between days 25 and 30, indicating that those lesions could not be visualized during the luteal phase of the cycle.

Nine of the 39 lesions were $<1 \mathrm{~cm}$ in size and 30 were $\geq 1 \mathrm{~cm}$, as shown by hysteroscopy. Lesions of $<1 \mathrm{~cm}$ were detected by TVS during the ovulatory and luteal phases (days 16-19) of the cycle and none of those were detectable during the follicular phase (days 1-12). Only three of the lesions were detectable in the middle to late luteal phase (days 20-30).

All lesions $\geq 1 \mathrm{~cm}$ were detectable during the ovulatory and early luteal phases. Of those, 26 (67\%) were visualized during the follicular phase and 27 (69\%) were detected during the middle to late luteal phase. In summary, all 39 lesions were detected during the early luteal and ovulatory phases.

According to these data, the highest sensitivity, specificity, positive predictive value (PPV), and negative predictive value (NPV) ofTVS were at the beginning of the luteal phase (days 16-19), confirming this time segment as optimal for performing TVS (Table 1).

\section{Discussion}

IULs are a relatively common finding in women of reproductive age, ${ }^{1,18}$ and their occurrence is even more frequent in

Table I Sensitivity, specificity, positive predictive values (PPVs), and negative predictive values (NPVs) of transvaginal sonography on different days of the menstrual cycle

\begin{tabular}{lllllll}
\hline $\begin{array}{l}\text { Day of } \\
\text { cycle }\end{array}$ & $\mathbf{N}$ & Yes* & Sensitivity & Specificity & PPV & NPV \\
\hline $1-4$ & 495 & 11 & $28.2 \%$ & $100 \%$ & $100 \%$ & $94 \%$ \\
$5-8$ & 490 & 16 & $41.2 \%$ & $100 \%$ & $100 \%$ & $95 \%$ \\
$9-12$ & 480 & 26 & $66.6 \%$ & $100 \%$ & $100 \%$ & $97 \%$ \\
$13-15$ & 471 & 35 & $89.7 \%$ & $100 \%$ & $100 \%$ & $99 \%$ \\
$16-19$ & 467 & 39 & $100 \%$ & $100 \%$ & $100 \%$ & $100 \%$ \\
$20-24$ & 476 & 30 & $76.9 \%$ & $100 \%$ & $100 \%$ & $98 \%$ \\
$25-30$ & 487 & 19 & $48 \%$ & $100 \%$ & $100 \%$ & $95.8 \%$ \\
\hline
\end{tabular}

Note: *Refers to the number on transvaginal sonography, on which the lesions were seen.

Abbreviation: N, number. women who have trouble conceiving. As far as the authors are aware, this is the first study that has attempted to evaluate the diagnostic accuracy of TVS in diagnosing intrauterine pathologies in infertile women during different phases of their menstrual cycle.

The main finding of this study is that the efficiency of TVS is highly affected by the phase of the ovulatory cycle during which the procedure is performed. This was especially apparent in the diagnosis of lesions of $<1 \mathrm{~cm}$, of which only one-third could be detected in the middle to late luteal phase, while all lesions were detectable in the ovulatory phase and at the beginning of the luteal phase. During the these parts of these two phases, all lesions $\geq 1 \mathrm{~cm}$ were detected, while only about $67 \%-69 \%$ of those were detected in other phases of the cycle. This indicates that the ovulatory phase and the beginning of the luteal phase are the optimal phases of the cycle to perform TVS to detect intrauterine pathologies. TVS sensitivity, specificity, PPV, and NPV during this phase (days 16-19), in comparison with SHG, reached 95\%, 98\%, 95.1\%, and 98\%, respectively (Table 2).

There are discordant reports of the sensitivity and specificity of TVS in the diagnosis of intrauterine pathologies ${ }^{6,13,15,19-23}$ (Table 3, Figure 1), while there are no such major discrepancies in the evaluation of SHG or hysteroscopy. Since the authors' results clearly indicate that menstrual cycle phase may be an important factor in the efficiency of TVS, previous conflicting reports may be due to the fact that TVS is performed on various days of the ovulatory cycle, while hysteroscopy and SHG are predominantly performed during the early follicular phase because menstrual bleeding decreases visualization of the uterine cavity and because they cannot be performed during the luteal phase since those procedures may interfere with ongoing pregnancy and lead to miscarriage or ectopic pregnancy. TVS, however, can be performed at any time without increased danger to the patient or to a potential embryo.

Since the sensitivity, specificity, PPV, and NPV of HSG compared with SHG was $29 \%, 98 \%, 100 \%$, and $78 \%$,

Table 2 Sensitivity, specificity, positive predictive values (PPVs), and negative predictive values (NPVs) of transvaginal sonography compared with sonohysterography

\begin{tabular}{lllll}
\hline Day of cycle & Sensitivity & Specificity & PPV & NPV \\
\hline $1-4$ & $26.8 \%$ & $98 \%$ & $84.6 \%$ & $80 \%$ \\
$5-8$ & $39 \%$ & $98 \%$ & $88.8 \%$ & $82.7 \%$ \\
$9-12$ & $63 \%$ & $98 \%$ & $92.8 \%$ & $88.8 \%$ \\
$13-15$ & $85.3 \%$ & $98 \%$ & $94.5 \%$ & $95.2 \%$ \\
$16-19$ & $95 \%$ & $98 \%$ & $95 \%$ & $98.2 \%$ \\
$20-24$ & $73.1 \%$ & $98 \%$ & $93.7 \%$ & $91.6 \%$ \\
$25-30$ & $46.3 \%$ & $98 \%$ & $90.4 \%$ & $84.5 \%$ \\
\hline
\end{tabular}


Table 3 Sensitivity, specificity, positive predictive values (PPVs), and negative predictive values (NPVs) of transvaginal sonography (TVS) in different studies (complementary to Figure I*)

\begin{tabular}{|c|c|c|c|c|c|}
\hline Study & Time TVS performed & Sensitivity & Specificity & PPV & NPV \\
\hline I. Shalev and Dicker ${ }^{13}$ & Day 9-13 & $100 \%$ & $96.3 \%$ & $91.3 \%$ & $100 \%$ \\
\hline 2. Dueholm et $\mathrm{al}^{22}$ & $\begin{array}{l}\text { Without relationship } \\
\text { to phase of cycle }\end{array}$ & $69 \%$ & $83 \%$ & $71 \%$ & $82 \%$ \\
\hline 3. Guven et $\mathrm{a}^{20}$ & $\begin{array}{l}\text { Without relationship } \\
\text { to phase of cycle }\end{array}$ & $78 \%$ & $38 \%$ & $61 \%$ & $59 \%$ \\
\hline 4. Alborzi et al ${ }^{19}$ & $\begin{array}{l}\text { Without relationship } \\
\text { to phase of cycle }\end{array}$ & $72 \%$ & $92 \%$ & $94 \%$ & $65 \%$ \\
\hline 5. Kelekci et $\mathrm{a}^{21}$ & Early proliferative phase & $56.2 \%$ & $72 \%$ & $56.3 \%$ & $72 \%$ \\
\hline 6. Loverro et $\mathrm{al}^{15}$ & Day 6-10 & $84.5 \%$ & $98.7 \%$ & $98 \%$ & $89.2 \%$ \\
\hline 7. Valentin ${ }^{23}$ & $\begin{array}{l}\text { Without relationship } \\
\text { to phase of cycle }\end{array}$ & $69 \%$ & $83 \%$ & $71 \%$ & $82 \%$ \\
\hline 8. Grimbizis et $\mathrm{al}^{24}$ & $\begin{array}{l}\text { Without relationship } \\
\text { to phase of cycle }\end{array}$ & $44.8 \%$ & $77.5 \%$ & - & - \\
\hline 9. Present study & Day 16-19 & $95 \%$ & $98 \%$ & $95.1 \%$ & $98 \%$ \\
\hline 10. Shalev et $\mathrm{al}^{25}$ & Follicular phase & $71.4 \%$ & $100 \%$ & $100 \%$ & $97.1 \%$ \\
\hline
\end{tabular}

Note: *Studies I-10 correlate with rows I-10 in Figure I.

respectively, it suggests that HSG is a very limited method for the diagnosis of IULs, as previously reported. ${ }^{8}$ If fallopian tubes patency does not need to be assessed, the authors suggest TVS as the first method to assess the intrauterine cavity, although it may not be able to detect smaller pathological structures.
Delicate adhesions in two patients were not detected by TVS but were shown by SHG. However, using TVS with saline infusion has been shown to reach the sensitivity of hysteroscopy in the diagnosis of IULs. ${ }^{23}$ If hysteroscopy is inaccessible, performing TVS at the ovulatory or early luteal phase, in combination with SHG, may be an optimal approach
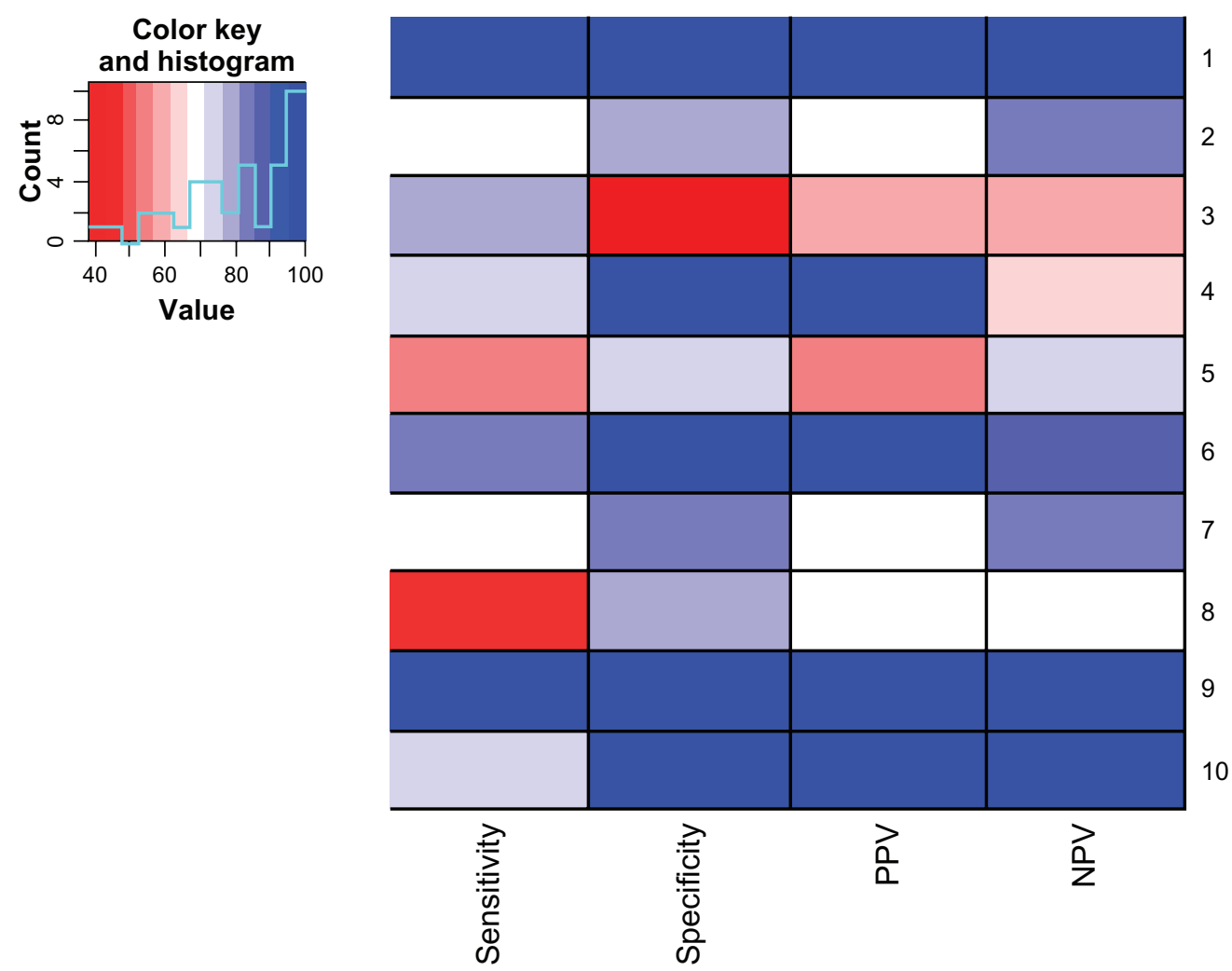

Figure I Heat map of outcomes of various studies assessing transvaginal sonography (complementary to Table $3^{*}$ ).

Note: *Rows I-10 correlate with studies I-10 in Table 3.

Abbreviations: PPV, positive predictive value; NPV, negative predictive value. 
for evaluating the integrity of intrauterine cavity. Unlike hysteroscopy, SHG provides additional information about the adnexa and the combined techniques provide invaluable data about the reproductive system of infertile females.

In conclusion, the data indicate that the accuracy of TVS in the diagnosis of IULs is highly dependent on the ovulatory cycle phase and, if performed during the early luteal phase, its specificity reaches $98 \%$. The authors' results indicate that the optimal time to perform TVS to detect intrauterine pathologies is during the ovulatory or early luteal phases. All lesions, irrespective of their size, were detected during this cycle phase (ovulatory or early luteal phases, days 16-19).

In addition, if confirmed by further studies, TVS accompanied by SHG, when performed at the optimal ovulatory cycle phase, may represent a future cost-effective alternative to hysteroscopy in the evaluation of the intrauterine cavity.

\section{Disclosure}

The authors declare no conflicts of interest in this work.

\section{References}

1. Pérez-Medina T, Bajo-Arenas J, Salazar F, et al. Endometrial polyps and their implication in the pregnancy rates of patients undergoing intrauterine insemination: a prospective, randomized study. Hum Reprod. 2005;20:1632-1635.

2. Melki LA, Oliveira MA, Oliveira HC. Can transvaginal sonography avoid the diagnostic complementary hysteroscopy in the detection of the endometrial polyp? Brazilian Journal of Videoendoscopic Surgery. 2008;1:71-75.

3. Berek JS, editor. Berek and Novak's Gynecology. 14th ed. Philadelphia, PA: Lippincott Williams \& Wilkins, 2007.

4. Prevedourakis C, Loutradis D, Kalianidis C, Makris N, Aravantinos D. Hysterosalpingography and hysteroscopy in female infertility. Hum Reprod. 1994;9:2353-2355.

5. Hajishafiha M, Zobairi T, Zanjani VR, Ghasemi-Rad M, Yekta Z, Mladkova N. Diagnostic value of sonohysterography in the determination of fallopian tube patency as an initial step of routine infertility assessment. J Ultrasound Med. 2009;28:1671-1677.

6. Soares SR, Barbosa dos Reis MM, Camargos AF. Diagnostic accuracy of sonohysterography, transvaginal sonography, and hysterosalpingography in patients with uterine cavity diseases. Fertil Steril. 2000;73:406-411.

7. Colacurci N, De Franciscis P, Fornaro F, Fortunato N, Perino A. The significance of hysteroscopic treatment of congenital uterine malformations. Reprod Biomed Online. 2002;4 Suppl 3:52-54.

8. Debnath J, Satija L, Sharma R, Singh H, Mohan R, Khanna SK. Transvaginal saline infusion sonohysterography: initial results. Armed Forces Med J India. 2000:135-139.
9. Kurabayashi T, Kase H, Suzuki M, Sugaya S, Fujita K, Tanaka K. Endometrial abnormalities in infertile women. J Reprod Med. 2003;48: 455-459.

10. Dijkhuizen FP, Brölmann HA, Potters AE, Bongers MY, Heinz AP. The accuracy of transvaginal ultrasonography in the diagnosis of endometrial abnormalities. Obstet Gynecol. 1996;87:345-349.

11. Stadtmauer L, Grunfeld L. The significance of endometrial filling defects detected on routine transvaginal sonography. $J$ Ultrasound Med. 1995;14:169-172; discussion 173-174.

12. Narayan R, Goswamy RK. Transvaginal sonography of the uterine cavity with hysteroscopic correlation in the investigation of infertility. Ultrasound Obstet Gynecol. 1993;3:129-133.

13. Shalev J, Dicker D. Predictive values of transvaginal sonography in specifying bicornuate and septate uterus? Fertil Steril. 2003;79:1254.

14. Parsons AK, Lense JJ. Sonohysterography for endometrial abnormalities: preliminary results. J Clin Ultrasound. 1993;21:87-95.

15. Loverro G, Nappi L, Mei L, Giacomoantonio L, Carriero C, Tartagni M. Evaluation of functional ovarian reserve in 60 patients. Reprod Biomed Online. 2003;7:200-204.

16. Fabres C, Alam V, Balmaceda J, Zegers-Hochschild F, Mackenna A, Fernandez E. Comparison of ultrasonography and hysteroscopy in the diagnosis of intrauterine lesions in infertile women. JAmAssoc Gynecol Laparosc. 1998;5:375-378.

17. Alatas C, Aksoy E, Akarsu C, Yakin K, Aksoy S, Hayran M. Evaluation of intrauterine abnormalities in infertile patients by sonohysterography. Hum Reprod. 1997;12:487-490.

18. Stamatellos I, Apostolides A, Stamatopoulos P, Bontis J. Pregnancy rates after hysteroscopic polypectomy depending on the size or number of the polyps. Arch Gynecol Obstet. 2008;277:395-399.

19. Alborzi S, Parsanezhad ME, Mahmoodian N, Alborzi M. Sonohysterography versus transvaginal sonography for screening of patients with abnormal uterine bleeding. Int J Gynaecol Obstet. 2007;96:20-23.

20. Guven MA, Bese T, Demirkiran F, Idil M, Mgoyi L. Hydrosonography in screening for intracavitary pathology in infertile women. Int J Gynaecol Obstet. 2004;86:377-383.

21. Kelekci S, Kaya E, Alan M, Alan Y, Bilge U, Mollamahmutoglu L. Comparison of transvaginal sonography, saline infusion sonography, and office hysteroscopy in reproductive-aged women with or without abnormal uterine bleeding. Fertil Steril. 2005;84:682-686.

22. Dueholm M, Lundorf E, Hansen ES, Ledertoug S, Olesen F. Evaluation of the uterine cavity with magnetic resonance imaging, transvaginal sonography, hysterosonographic examination, and diagnostic hysteroscopy. Fertil Steril. 2001;76:350-357.

23. Valentin L. Transvaginal sonography in gynaecology. Reviews in Gynaecological and Perinatal Practice. 2003;4:50-57.

24. Grimbizis GF, Tsolakidis D, Mikos T, et al. A prospective comparison of transvaginal ultrasound, saline infusion sonohysterography, and diagnostic hysteroscopy in the evaluation of endometrial pathology. Fertil Steril. 2010;94:2720-2725.

25. Shalev J, Meizner I, Bar-Hava I, Dicker D, Mashiach R, Ben-Rafael Z. Predictive value of transvaginal sonography performed before routine diagnostic hysteroscopy for evaluation of infertility. Fertil Steril. 2000;73:412-417.
International Journal of Women's Health

\section{Publish your work in this journal}

The International Journal of Women's Health is an international, peerreviewed open-access journal publishing original research, reports, reviews and commentaries on all aspects of women's healthcare including gynecology, obstetrics, and breast cancer. Subject areas include: Chronic conditions (migraine headaches, arthritis, osteoporosis);

\section{Dovepress}

Endocrine and autoimmune syndromes; Sexual and reproductive health; Psychological and psychosocial conditions. The manuscript management system is completely online and includes a very quick and fair peer-review system. Visit http://www.dovepress.com/ testimonials.php to read real quotes from published authors. 